\title{
Prevalence of health problems among the regular alcohol users (chronic alcoholics) in urban and rural area of district Amritsar: Punjab: India
}

\author{
Singh G. ${ }^{1}$, Mitra Y.. ${ }^{*}$, Singh J. ${ }^{3}$, Padda A. ${ }^{4}$ \\ DOI: https://doi.org/10.17511/ijphr.2019.i1.05
}

${ }^{1}$ Gumreet Singh, Professor, Department of Community Medicine, Punjab Institute of Medical Sciences, Jalandhar, Punjab, India.

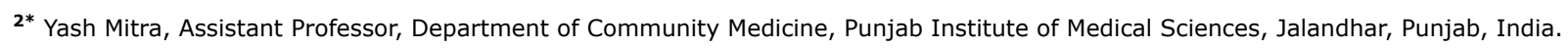

3 Jagjeet Singh, Professor and Head (Ex), Department of Community Medicine, Government Medical College, Patiala, Punjab, India.

${ }^{4}$ A.S. Padda, Professor and Head (Ex), Department of Community Medicine, Government Medical College, Amritsar, Punjab, India.

Introduction- The menace of alcohol abuse in the Punjab State is not less prevalent than the rest of India. Alcoholism in Punjab is assuming an alarming proportion. Chronic alcohol abuse may lead to mal-absorption of various substances, calcium, vitamin B complex and iron leading to health problems. Objective- To assess the impact of prolonged alcohol use on different systems of the body leading to health problems. Methods-The present cross-sectional study was conducted in rural and urban field practice areas attached to the Department of Community Medicine, Government Medical College, Amritsar. The target population in urban area was 847 and in rural area it was 737. Three sets of proforma i.e. A, B and C were evolved. Results- Majority of the regular alcohol users were suffering from different liver diseases like fatty infiltration 60 (56.08\%), alcoholic hepatitis 25 (23.36\%), alcoholic cirrhosis 10 (9.35\%). In cardiovascular system assessment, 23 (21.50\%) were suffering from severe hypertension. Recurrent chest infections were observed in 32 (29.91\%). In CNS assessment it was observed that 37 (34.58\%) were suffering from loss of recent memory and $51(47.68 \%)$ from insomnia. Delayed ejaculation was observed in $30(28.04 \%)$. Conclusion- There is urgent need for further indepthcommunity based research in a larger sample and for a longer period, should be undertaken jointly by the specialists from the medical profession, social scientists and enforcement agencies to have real picture of alcohol consumption and its effect on health.

Keywords: Regular users, Chronic alcoholics, Malnutrition, Anaemia, Hypertension, Hepatitis, Liver disease, Tremors, Insomnia

Corresponding Author

Yash Mitra, Assistant Professor, Department of Community Medicine, Punjab Institute of Medical Sciences, Jalandhar, Punjab, India.

Email: mitrayash@yahoo.com
How to Cite this Article

Singh G, Mitra Y, Singh J, Padda AS. Prevalence of health problems among the regular alcohol users (chronic alcoholics) in urban and rural area of district Amritsar: Punjab: India. Public Health Rev Int J Public Health Res. 2019;6(1):35-40.

Available From

https://publichealth.medresearch.in/index.php/ijphr/ article/view/98
To Browse

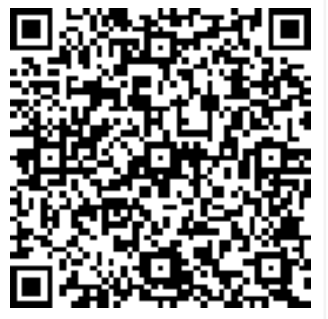

Manuscript Received 2019-02-02

Conflict of Interest No
Review Round 1 2019-02-10

Funding

Nil

Review Round 2
2019-02-16
Ethical Approval
Yes

Review Round 2

Yes
Review Round 3

Plagiarism X-checker $6 \%$
Accepted 2019-02-20

() 2019 by Gumreet Singh, Yash Mitra, Jagjeet Singh, A.S. Padda and Published by Siddharth Health Research and Social Welfare Society. This is an Open Access article licensed under a Creative Commons Attribution 4.0 International License ttps://creativecommons.org/licenses/by/4.0/ unported [CC BY 4.0]. 


\section{Introduction}

Alcoholism is a disorder characterised by pathological pattern of alcohol use that causes a serious impairment in social or occupational functioning, is termed as alcohol abuse, or, if tolerance or withdrawal is present, it is called alcohol dependence.

Alcoholism, is a progressive and permanent disease. Apart from this, excessive use of alcohol effects the functioning of various systems in the body and leads to several complications: Alcohol related problems or diseases affect $5-10 \%$ of World's population each year and accounted for approximately $3 \%$ of the global

Burden of the diseases. 2 million deaths occur world-wide each year due to alcohol consumption, of which about $50 \%$ are from cirrhosis of liver, 35\% from cancer of liver or oesophagus, $10 \%$ from alcohol dependence syndrome and about 5\% from injuries caused by motor vehicles [1].

In USA, the alcohol related problems cost nearly $\$$ 43 billion/year as a result of lost production, motor vehicle accidents, crime, social problems and demand for health care services [2]. India has always been described as an abstinant culture i.e. society where the majority do not drink and have clearly negative attitudes towards alcohol use.

In such a situation, one would expect the overall consumption level to be generally low. However, studies show that alcohol use is infact fairly wide spread and social attitudes are more ambivalent than negative. The menace of alcohol abuse in the Punjab State is not less prevalent than the rest of India. Alcoholism in Punjab is assuming an alarming proportion.

Alcoholism is a chronic illness, psychic, somatic or psychosomatic, which manifests itself as a disorder of behaviour. It is characterised by the repeated drinking of alcoholic beverages, to an extent that exceeds customarily, dietary use or compliance with the social customs of the community and that interferes with the drinker's health or the social or economic functioning.

The most prevalent disorders of alcohol use were diseases of the GIT, Liver, Gall bladder and Pancreas, Bronchitis, Emphysema and Asthma. Involvement of CVS i.e. hypertension, psychiatric disorders associated with alcoholism was neurosis. There are present various personality disorders.
Chronic alcohol abuse may lead to malabsorption of various substances, calcium, Vitamin B complex vitamins and iron [3].

Objectives-To determine the prevalence of alcohol related health problems among the regular alcohol users (chronic alcoholics).

\section{Methods}

Type of Study: Community based cross-sectional study

Sampling Method: Random Sampling Method was used for sample collection. The present study was conducted in rural and urban field practice areas attached to the Department of Community Medicine, Government Medical College, Amritsar, covering a population of 10000 in each area by adopting the systemic random sampling technique. Out of a total population of 10000 (5000 each from urban i.e.

Urban Training Health Centre, Chowk Fowara, Amritsar city and rural i.e. village Gumtala Field Practice areas by selecting 200 houses from each area (considering a total average number of family members as five). The target population in urban area was 847 and in rural area it was 737. Three sets of proforma i.e. A, B and C were evolved. Study was carried out in the year 1995-1996.

The assessment of health status of regular alcohol user was done by conducting the general physical examination and systemic examination.The information and findings thus obtained were recorded in pre-structured and pre-tested proformaC. The data thus obtained was analysed and valid conclusions were drawn.

Inclusion Criteria: The person consuming $200 \mathrm{ml}$ or more of $40-60 \%$ concentration of alcohol daily, for four days or more in a week for the last five years or more and greater than 10 years of age, was considered as an alcoholic/ regular user and was included in the study.

The regular users were further classified into mild $(30 \mathrm{ml}-120 \mathrm{ml})$, moderate $(120-200 \mathrm{ml})$ and heavy drinkers (200-320 $\mathrm{ml}$ and above). Secondly who has given his written consent to participate in the study [1].

Exclusion Criteria: The alcoholics who has not given written consent and was not fulfilling the criteria for regular alcohol user.

Statistical Methods: It is a Cross-sectional 
Observation study based on the general physical examination of the participants, so the data regarding various diseases was collected and depicted in the tabulated form. Hence no statistical methods were employed.

Ethical Consideration and Permission: The ethical consideration and permission was obtained from the Institutional Ethical Committee

\section{Results}

Chronic alcoholism is a disease prevalent all over the world. The aim of this study was to find the proportion of involvement of different systems of the body by the regular use of the alcohol in this part of the country.

Table 1 depicts that out of total 107 regular alcohol users in urban and rural areas, 77 (72.12\%) had one or the other disease in the past.

Majority of the alcoholics were suffering from common ailments of gastritis, $73(68.22 \%)$, jaundice $26(24.29 \%)$, loss of weight and appetite 64 (59.81\%).

In the general physical examination of the alcoholics, it was observed that majority 98 $(91.58 \%)$ of them were suffering from Mild, Moderate and severe anaemia. Malnutrition 64 (59.81\%), weight loss $86(80.37 \%)$, tremors 73 (68.22\%), poor oro-dental and personal hygiene $100(93.45 \%)$ and $42(39.25 \%)$ respectively was observed in the total urban and rural population.

Table 2 shows that on examination of gastrointestinal system (GIS), majority of the regular users found to be suffering from different liver diseases i.e. Fatty liver 60 (56.08\%), alcoholic hepatitis 25 (23.36\%), alcoholic cirrhosis 10 $(9.33 \%)$, oesophageal varicosity $7(6.54 \%)$, chronic pancreatitis $5(4.67 \%)$.

On examination of the cardiovascular system, Table 3 shows that mild hypertension (Grade I, B.P.140$180 / 90-105 \mathrm{mmHg}$ ) in $5(4.67 \%)$, moderate (Grade II, B.P.180-210/105-120 mmHg) in $14(13.08 \%)$ and severe (Grade III B.P. $>210 />120 \mathrm{mmHg}$ ) in 23 $(21.50 \%)$ was observed.

Table 4 shows that on examination of respiratory system,chronic bronchitis was observed in 16 $(14.95 \%)$, asthma $14(13.08 \%)$, Tuberculosis in 2 $(1.87 \%)$ and recurrent chest infections in 32 (29.91\%) of the alcoholics.
In Table 5, the assessment of central nervous system shows that $37(34.58 \%)$ were suffering from loss of recent memory and 51 (47.68\%) from insomnia which is a common feature of chronic alcoholism. Alcoholic dementia was observed in 60 (56.07\%), Disturbance of memory and thought 29 $(27.10 \%)$, impaired social and occupational functions $14(13.08 \%)$, withdrawal stage behaviour 17 (15.89\%).

Polyneuritis (Numbness, Tingling sensation, Pin pricks was found in 50 (46.72\%), Swelling in legs, Fatigue tenderness in $14(13.09 \%)$ and pain in Calf muscles wasting of muscles 14 (13.09\%).

Table 6 shows that as per the assessment of the reproductive system, it was observed that 91 $(83.05 \%)$ and $35(32.71 \%)$ were suffering from decreased sexual desire and performance respectively. The alcohol has direct effect on the sexual activity and performance, due to consumption of large amount of concentrated alcohol for a prolonged period.

\section{Discussion}

It may be concluded that alcohol is one of the beverage which is commonly used and socially accepted. It has an effect on almost every organ of the body, affecting, an individual's physical and mental health and also his socio-economic status.

No female used alcohol or any other drug in both urban and rural area, as taking of alcohol and other intoxicants by women is a taboo. Hence female population has been excluded from the assessment of the health status.10 regular alcohol users ( 7 in urban and 3 in rural) were not fulfilling the criteria for chronic alcoholics. They were consuming $<200$ $\mathrm{ml}$ for a period of $<5$ years.

The ill effects of alcohol on various organs of the body may be due to use of mostly concentrated home-made and country made liquor in rural area and country made or IMFL in urban area. The second factor was that people do not take much food along with alcohol and also due to prolonged use of alcohol.

The poor intake of food leads to anaemia and weight loss along with loss of appetite. Low economic status also creates economic problems for purchase of nutritious food for himself and family. Therefore due to these leading factors, the chronic alcoholics were suffering from one or the other morbidity pattern and majority of them were suffering from 
Different types of liver diseases i.e. fatty liver, alcoholic hepatitis and alcoholic cirrhosis.

This indicates that a large number of regular alcohol users in both the urban and rural areas were suffering from health problems in the past and even they were continuing to drink. In a study gastritis and dyspepsia was found in $70 \%$ of cases [4].

Anaemia was found in $90 \%$ of cases in this part of country (Amritsar; Punjab). Hillman (1964) Loss of weight was observed in $63 \%$ of cases. The difference between this study with that of Western countries is due to the fact that there is a very less quantity of food intake along with concentrated alcohol consumption in this part of the country [4] [5].

With the withdrawal of alcohol majority of them were suffering from tremors, $43(40.18 \%)$, craving and insomnia 21 (19.63\%) and morning headache, shakes, irrelevant speech, palpitation and dyspnoea by $9(8.41 \%)$. Tremors were also observed in $56 \%$ of alcoholics [4].

In two different studies the Liver enlargement regardless of the type of alcoholic liver disease was present in $82 \%$ of alcoholics in one of the study and it was $80 \%$ in the study conducted by another author [4] [6]. In this part of the country hypertension was observed in $16 \%$ of alcoholics whereas in western studies it was found as $18 \%$ [4] [7].

In western studies, chronic bronchitis and TB was observed in 4 (54\% and $1.73 \%$ respectively). Where as in this part of the country TB was found in $5 \%$ of alcoholics.

The incidence of tuberculosis in rural population in this part of the country is due to the fact that they consume less food leading to malnutrition and decrease in the level of immunity causing various chest infections and TB. In urban area, the incidence of chest infections is also high due to the same reasons [3] [4].

In one of the western studies neuropathy was found in $10 \%$ of alcoholics whereas in this part of the country, the neuropathy was found in $26 \%$ of alcoholics and in another study in a western country it was found as $21 \%$ respectively.

The high incidence of neuropathy in this study might be due to increased prevalence and free availability of alcohol which is very concentrated. The second factor might be poor intake of nutritious food with
Less quantity.

Kumar (2002) in a study observed that the clients often feel guilt, shame, embarrassment, depression $(47 \%)$, anxiety (55\%) and feel isolated as a result of drug misuse and many (35\%) had frequent thoughts of suicide [2] [4] [7][8] [13].

In a study conducted to examine the association between partner alcohol problems and selected physical and mental health outcomes, it was found that physical health measures included poor health, mental health i.e. mood and anxiety disorders.

Alcohol problems were more likely to experience victimization, injury, mood disorders, anxiety disorders and being in fair or poor health than women whose partners did not have alcohol problems [9].

In an epidemiological survey conducted to estimate the pattern of alcohol and other substance dependence in rural and slum population of Chandigarh, $6.88 \%$ individuals fulfilled dependence criteria of ICD-10. Alcohol was the primary substance of dependence for majority of urban slum and rural areas.

Majority of them reported having health related complications $(85.71 \%)$ due to drug dependence. The psycho-social as well as the economic problems can produce an environment of chaos and misery. Families of the alcoholics have been described as experiencing increasing stress, anxiety, loneliness, depressive episodes, guilt and suicide tendencies.

Contributing further to the impact of drug abuse on the family, psychological problems can have profound effect on the vulnerability of the family [10]. Kley et al (1975) observed loss of sexual activity and performance in 40 to $77 \%$ of male alcoholics [11].

\section{Conclusion}

There is an urgent need for to conduct furtherindepth community based research in a larger sample and for a longer period jointly by the specialists from the medical profession, social sciences, and enforcement agencies to have a real picture of alcohol consumption and its effects on health and socio-economic consequences affecting the individual, family and community. This will help in developing a comprehensive programme to tackle the alcohol menace which is destroying the social fabric of the family, society and nation leading to 
Great loss of productivity and overall development.

Table-1: General Physical Examination of Regular Alcohol Users

\begin{tabular}{|l|l|l|l|l|l|l|}
\hline \multirow{2}{*}{} & \multicolumn{2}{|c|}{$\begin{array}{c}\text { Urban } \\
(\mathrm{N}=41)\end{array}$} & \multicolumn{2}{|c|}{$\begin{array}{c}\text { Rural } \\
(\mathrm{N}=66)\end{array}$} & \multicolumn{2}{|c|}{$\begin{array}{c}\text { Combined } \\
(\mathrm{N}=\mathbf{1 0 7})\end{array}$} \\
\cline { 2 - 8 } & No. & $\%$ age & No. & $\%$ age & No. & $\%$ age \\
\hline $\begin{array}{l}\text { Anaemia (Mild, Moderate, } \\
\text { Severe) }\end{array}$ & 37 & 90.24 & 61 & 92.43 & 98 & 92.58 \\
\hline Malnutrition & 22 & 43.65 & 42 & 63.63 & 64 & 59.81 \\
\hline Weight Loss & 30 & 73.17 & 56 & 84.85 & 86 & 80.37 \\
\hline Tremors & 25 & 60.97 & 48 & 72.72 & 73 & 68.22 \\
\hline Poor Orodental Hygiene & 37 & 90.24 & 63 & 95.45 & 100 & 93.45 \\
\hline Personal Hygiene & 13 & 31.71 & 29 & 43.93 & 42 & 39.25 \\
\hline
\end{tabular}

Table-2: Showing Pattern of Ailments in GIT in Chronic Alcohol Users

\begin{tabular}{|l|l|l|l|l|l|l|}
\hline \multirow{2}{*}{} & \multicolumn{2}{|c|}{$\begin{array}{c}\text { Urban } \\
(\mathrm{N}=41)\end{array}$} & \multicolumn{2}{c|}{$\begin{array}{c}\text { Rural } \\
(\mathrm{N}=66)\end{array}$} & \multicolumn{2}{c|}{ Combined (N=107) } \\
\cline { 2 - 8 } & No. & $\%$ age & No. & $\%$ age & No. & $\%$ age \\
\hline $\begin{array}{l}\text { Oesophageal } \\
\text { Varicosity }\end{array}$ & 4 & 9.76 & 3 & 4.55 & 7 & 6.54 \\
\hline Fatty Liver & 21 & 51.22 & 39 & 59.10 & 60 & 56.08 \\
\hline Alcoholic Hepatitis & 9 & 21.95 & 16 & 24.24 & 25 & 23.36 \\
\hline Alcoholic Cirrhosis & 4 & 9.76 & 6 & 9.10 & 10 & 9.35 \\
\hline Pancreatitis & 3 & 7.31 & 2 & 3.01 & 5 & 4.67 \\
\hline
\end{tabular}

\section{Table-3: Showing Hypertension (CVS} Problem).

\begin{tabular}{|c|c|c|c|c|c|c|c|}
\hline \multirow[t]{2}{*}{$\begin{array}{l}\text { Age in } \\
\text { Years }\end{array}$} & \multirow[t]{2}{*}{ Hypertension } & \multicolumn{2}{|c|}{$\begin{array}{c}\text { Urban } \\
(\mathrm{N}=41)\end{array}$} & \multicolumn{2}{|c|}{$\begin{array}{c}\text { Rural } \\
(\mathrm{N}=66)\end{array}$} & \multicolumn{2}{|c|}{$\begin{array}{l}\text { Combined } \\
(\mathrm{N}=107)\end{array}$} \\
\hline & & & $\begin{array}{l}\% \\
\text { age }\end{array}$ & & $\begin{array}{l}\% \\
\text { age }\end{array}$ & No. & $\%$ age \\
\hline $10-20$ & $\begin{array}{l}\text { Normotensive } 110-140 / 60- \\
90 \mathrm{mmHg}\end{array}$ & 24 & 58.54 & 41 & 62.12 & 65 & 60.75 \\
\hline $20-30$ & $\begin{array}{l}\text { Mild (Grade I) 140-180/90- } \\
105 \text { mmHG }\end{array}$ & 2 & 4.88 & 3 & 4.35 & 5 & 4.67 \\
\hline $30-40$ & $\begin{array}{l}\text { Moderate (Grade II) } 180- \\
210 / 105-120 \mathrm{mmHG}\end{array}$ & 5 & 12.19 & 9 & 13.64 & 14 & 13.08 \\
\hline$\left|\begin{array}{l}40-50 \text { and } \\
\text { above }\end{array}\right|$ & $\begin{array}{l}\text { Severe (Grade III) >210/ } \\
<120 \mathrm{~mm} \mathrm{HG}\end{array}$ & 10 & 25.39 & 13 & 19.69 & 23 & 21.50 \\
\hline & & 17 & 41.46 & 25 & 37.88 & 42 & 39.25 \\
\hline
\end{tabular}

NB: Classification of hypertension is according to WHO (1966) criteria.

Table-4: Showing Pattern of Morbidity of Respiratory System in Regular Users.

\begin{tabular}{|l|l|l|l|l|l|l|}
\hline \multirow{2}{*}{ Morbidity } & \multicolumn{3}{|l|}{ Urban $(\mathrm{N}=\mathbf{4 1})$} & \multicolumn{2}{l|}{ Rural $(\mathrm{N}=\mathbf{6 6})$} & \multicolumn{2}{l|}{ Combined $(\mathrm{N}=\mathbf{1 0 7})$} \\
\cline { 2 - 7 } & No. & $\%$ age & No. & $\%$ age & No. & $\%$ age \\
\hline Chromic bronchitis & 3 & 7.32 & 13 & 19.69 & 16 & 14.95 \\
\hline Asthma & 5 & 12.19 & 9 & 13.64 & 14 & 13.08 \\
\hline TB & - & - & 2 & 3.03 & 2 & 1.87 \\
\hline & 8 & 19.51 & 24 & 36.36 & 32 & 29.91 \\
\hline
\end{tabular}

\begin{tabular}{|l|l|l|l|l|l|l|}
\hline Recurrent Chest Infection & 14 & 34.15 & 18 & 27.28 & 32 & 29.91 \\
\hline No ailment & 19 & 36.34 & 24 & 36.36 & 43 & 40.19 \\
\hline
\end{tabular}

Table-5: Showing Morbidity of Polyneuritis in Central Nervous System.

\begin{tabular}{|l|c|c|c|c|c|c|}
\hline \multirow{2}{*}{ Morbidity } & \multicolumn{2}{|c|}{$\begin{array}{c}\text { Urban } \\
(\mathrm{N}=41)\end{array}$} & \multicolumn{2}{|c|}{$\begin{array}{c}\text { Rural } \\
(\mathrm{N}=66)\end{array}$} & \multicolumn{2}{|c|}{$\begin{array}{c}\text { Combined } \\
(\mathrm{N}=107)\end{array}$} \\
\cline { 2 - 7 } & No. & $\%$ age & No. & $\%$ age & No. & $\%$ age \\
\hline $\begin{array}{l}\text { Numbness tingling sensation Pin } \\
\text { Pricks }\end{array}$ & 19 & 46.34 & 31 & 46.96 & 50 & 46.72 \\
\hline $\begin{array}{l}\text { Swelling in legs fatigue, tenderness } \\
\text { pain in calf muscle }\end{array}$ & 5 & 12.19 & 9 & 13.64 & 14 & 13.09 \\
\hline Wasting of muscles feeling coldness & 8 & 19.52 & 6 & 9.09 & 14 & 13.09 \\
\hline Total & 32 & 78.05 & 46 & 69.69 & 78 & 72.89 \\
\hline
\end{tabular}

Table-6: Showing Morbidity in Reproductive Systems.

\begin{tabular}{|l|c|c|c|c|c|c|}
\hline \multirow{2}{*}{ Morbidity } & \multicolumn{2}{|c|}{$\begin{array}{c}\text { Urban } \\
(\mathrm{N}=\mathbf{4 1})\end{array}$} & \multicolumn{2}{c|}{$\begin{array}{c}\text { Rural } \\
(\mathrm{N}=\mathbf{6 6})\end{array}$} & \multicolumn{2}{c|}{$\begin{array}{c}\text { Combined } \\
(\mathbf{N}=\mathbf{1 0 7})\end{array}$} \\
\cline { 2 - 8 } & No. & $\%$ age & No. & $\%$ age & No. & $\%$ age \\
\hline Decreased sexual desire & 32 & 78.05 & 59 & 89.39 & 91 & 85.04 \\
\hline $\begin{array}{l}\text { Decreased Sexual Performance } \\
\text { Impotency) }\end{array}$ & 10 & 24.39 & 25 & 37.88 & 35 & 32.71 \\
\hline Delayed ejaculation & 11 & 26.82 & 19 & 28.79 & 30 & 28.04 \\
\hline
\end{tabular}

\section{Reference}

01. World Development Report. Investing in health. Published for the World Bank, Oxford University Press, Oxford, New York. 88-89;1993.

[Crossref]

02. Schuckit. 1981 b-c- Alcohol consumption and pre-natal development. springer 3.

[Crossref]

03. Ranganathan. Alcoloism- An AppraisalShodhganga. By Keller and Effron. 1994;57. [Crossref]

04. Singh $P$, et al. Rate of prevalence of physical and mental changes in alcoholism. Thesis submitted for the degree of MD (Medicine) Guru Nanak Dev University, Amritsar. 1991.

[Crossref]

05. Galambos J. Gastroenterology Vol-5 by Edward Buck. Published by WB Saunders Company, Philadel-phia. 1985.

[Crossref]

06. Hillman (1964). Biology of alcoholism Benjamin and Begleiter. Published by Plenum Press, New York. 3;532, 1974.

[Crossref] 
07. Mendelson J, Babu T, Mello NK. Alcoholism and prevalence of medical and psychiatric disorders. Journal of Studies on Alcohol. 47;361,1986.

[Crossref]

08. Skinner $\mathrm{H}$, Holt S, Israel Y. Early identification of alcohol abuse, clinical and laboratory indicators. CMA Journal. 124;1279,1981.

[Crossref]

09. Wood ME. Assessment of chronic alcoholism by Medical Examination. New Zealand Medical Journal. 99;326,1986.

[Crossref]
10. Chaval BS, et al. Prevalence of alcohol and drug dependence in rural and slum population of Chandigarh- A community survey. Indian J Psychiatry. 2007;Jan-Mar;39(1)44-48. doi: [Article] [Crossref]

11. Kley, et al. Sex, alcohol and the developing fetus. Acta Endocrinol. 79;275-85;1975a.

[Crossref]

12. Morgan M. Alcohol and nutrition. Brit Med Bull. $38 ; 21 ; 1982$.

[Crossref]

13. Reuler GD. Wernicke's encephalopathy. New Eng Jour Med. 312;1035;1985.

[Crossref] 